\title{
Observer Design and Implementation for Packed-Bed Thermal Energy Storage Systems
}

\author{
Cristian Schirru, Alessandro Pisano, Elio Usai
}

\begin{abstract}
This paper investigates the problem of designing a state observer for a Packed Bed Thermal Energy Storage System. In previous studies (see e.g. [21]), a mathematical model of the system, taking the form of two coupled partial differential equations, was derived and validated through comparison with experimental measurements. In this paper, the previously derived model is approximated by a lumped linear time-invariant model and then employed to design a Luenberger state observer capable of reconstructing the solid and fluid temperature profiles on the basis of few collocated fluid temperature measurements. Theoretical design and experimental results are presented throughout the paper.
\end{abstract}

Keywords. Thermal Energy Storage System. Sensible heat storage, Packed-bed technology; State observer.

\section{INTRODUCTION}

Model-based control and advanced process monitoring of Distributed-Parameter Systems (DPSs), governed by Partial Differential Equations (PDEs), tipically require full-state information. However, the available measurements of DPS'are typically located on collocated points of the spatial domain, that motivates the need of the state observer [17-20,23]. There are two main approaches to observer design in DPSs. In the first approach, the system PDEs are preliminarily discretized (by finite differences or finite volume method) and the observer design is subsequently made with reference to the obtained finite-dimensional approximate model. In the second approach, the observer is designed as an infinite-dimensional DPS, and discretization (tipically by finite differences) is made after, at the implementation stage. In this paper we take the former approach, by transforming the mathematical model of the system under consideration into an approximate Linear Time Invariant (LTI) finite-dimensional dynamics, and then applying observer design techniques for finite-dimensional LTI systems. The basic state estimator for linear, lumped-parameter systems is the Luenberger observer [22], which will be the observer considered in the present work within the framework of a physically-motivated observer design problem for a certain energy-storage engineering apparatus.

Cristian Schirru

University of Cagliari, Dept. of Mechanical, Chemical and Material Engineering

Cagliari, Italy

Alessandro Pisano (corr. author), Elio Usai

University of Cagliari, Dept. of Electrical and Electronic Engineering.

Cagliari, Italy
Energy storage allows to efficiently exploit the renewable energy sources, which are inherently intermittent [1,2]. For concentrated solar power (CSP) plants in particular, storage of heat permits the uninterrupted production with and without the presence of the solar radiation [3-7]. In [5] the main thermal energy storage (TES) technologies were surveyed, and particularly the sensible heat storage and latent heat storage solutions were compared. Sensible heat storage raises the temperature of a solid medium, whereas the latent heat storage solution includes a phase change and implies the selection of an appropriate phase change material (PCM). Sensible heat storage is currently recognized as the simplest and cheapest method to store thermal energy [8]. Sensible heat TES systems with a single tank filled with solid material (packed bed) of high thermal capacity have been proposed, which are about $35 \%$ cheaper than the system with two tanks where the storage medium is the same heat transfer fluid (HTF) [9]. In the system with a single tank, the hot and cold fluids are separated by a moving region, called thermocline, which is characterized by a steep gradient of temperature that mainly depends on the characteristics of the solid storage material. Systems with packed bed (refractory ceramic materials, concrete, and limestone are most often utilized due to their relatively low cost and high thermal capacity) have been widely studied. Many published works (see e.g. [8, 10-14].) refer for numerical investigations to the mathematical PDE model originally developed by Schumann [12].

The main objective of the present work is to design and experimentally verify the performance of a state observer for a single tank packet-bed heat storage system. In a previous work [21] a mathematical model for the system in question was derived, taking the form of two coupled PDEs. In the present work, under sensible approximations, an approximate lumpedparameter LTI formulation of the model is derived. Such finite dimensional model is exploited to design a Luenberger observer. The performance of the observer are tested via comparison with temperature profiles acquired during experimental tests on a laboratory scale prototype operating at constant flow.

Section II recalls the considered mathematical model, with the Subsection II.A reporting the derivation of the approximate lumped-parameter LTI model. Section III presents the proposed Luenberger observer design and discusses the experimental investigation of the performance of the designed observer. Section IV draws some final conclusions and perspectives for next research. 


\section{MATHEMATICAL MODEL OF THE THERMAL STORAGE SYSTEM}

The Storage System consists of a thermally isolated cylinder filled with the packed bed solid material with high thermal capacity. During the loading phase, the hot HTF flows through the cylinder and conveys the thermal energy to the packed bed, whereas the reversed flow of the cold HTF is applied to collect the energy from the solid material in the discharging phase. The schematics and picture of the laboratory setup are shown in the Figures I.

The considered mathematical model is a LTNE (Local Thermal Non-Equilibrium) model based on Schumann's equations for heat transfer in a porous prism [12]. It consists of two coupled 1D PDEs which enable the calculation of the transient spatio-temporal evolution of the solid $\left(\mathrm{T}_{\mathrm{b}}(x, t)\right)$ and fluid $\left(\mathrm{T}_{\mathrm{f}}(x, t)\right)$ temperature under the assumptions that:

- The temperature gradient in the radial direction is zero

- The cylinder is thermally isolated

- The heat transfer rate from fluid to solid at any point is proportional to the average difference in temperature between fluid and solid at that point

The two coupled PDEs (see [12,15,16,21] for the derivation and further details) take the form

$$
\begin{aligned}
& \frac{\partial T_{f}}{\partial t}=-\frac{\dot{m}_{f} C_{P, f}}{\rho_{f} \varepsilon C_{V, f} A} \frac{\partial T_{f}}{\partial x}+\frac{h_{V}}{\rho_{f} \varepsilon C_{V, f}}\left(T_{b}-T_{f}\right), \\
& \frac{\partial T_{b}}{\partial t}=\frac{6 h}{\rho_{b} d_{S} C_{V, b}}\left(T_{f}-T_{b}\right), \\
& h=\frac{k_{f}}{d_{S}}\left(2+1.1\left(\frac{C_{P, f} \mu_{f}}{k_{f}}\right)^{1 / 3}\left(\frac{\dot{m}_{f} d_{S}}{A \mu_{f}}\right)^{0.6}\right), \\
& h_{V}=\frac{6 h(1-\varepsilon)}{d_{S}},
\end{aligned}
$$

where the meaning of the parameters is explained in the following table (the subscript $b$ refers to the solid bed and the subscript $f$ refers to the fluid respectively);

TABLE I. MEANING OF PARAMETERS

\begin{tabular}{|l|l|l|}
\hline Parameter & Unit & Description \\
\hline$\dot{m}_{f}$ & $\mathrm{~kg} / \mathrm{s}$ & Massic flow of the HTF \\
\hline$C_{\mathrm{V}, f} / C_{\mathrm{V}, b}$ & $\mathrm{~J} / \mathrm{kgK}$ & Specific heat at constant volume \\
\hline$C_{\mathrm{P}, f} / C_{\mathrm{P}, b}$ & $\mathrm{~J} / \mathrm{kgK}$ & Specific heat at constant pressure \\
\hline$\varepsilon$ & {$[0,1]$} & Bed void fraction \\
\hline$\rho_{\mathrm{f}} / \rho_{\mathrm{b}}$ & $\mathrm{kg} / \mathrm{m}^{3}$ & Density \\
\hline $\mathrm{A}$ & $\mathrm{m}^{2}$ & Tank cross section \\
\hline$h$ & $\mathrm{Wm} / \mathrm{K}$ & Heat transfer coefficient \\
\hline$d_{S}$ & $\mathrm{~m}$ & $\begin{array}{l}\text { Average diameter of the packet } \\
\text { bed particles }\end{array}$ \\
\hline$k_{f}$ & $\mathrm{~W} / \mathrm{mK}$ & Thermal conductivity of the fluid \\
\hline$\mu_{f}$ & Pa s & Dynamic viscosity of the fluid \\
\hline
\end{tabular}

Defining the next functions

$$
\begin{aligned}
& C_{1}\left(\dot{m}_{f}, T_{f}\right)=\frac{\dot{m}_{f} C_{P, f}}{\rho_{f} \epsilon C_{V, f} A} \\
& C_{2}\left(\dot{m}_{f}, T_{f}\right)=\frac{h_{v}}{\rho_{f} \epsilon C_{V, f}} \\
& C_{3}\left(\dot{m}_{f}, T_{f}, T_{b}\right)=\frac{6 h}{\rho_{b} * d_{S} * C_{V, b}}
\end{aligned}
$$

model (1)-(2) can be rewritten in the more compact form

$$
\begin{aligned}
& \frac{\partial T_{f}}{\partial t}=-C_{1} \frac{\partial T_{f}}{\partial x}+C_{2}\left(T_{b}-T_{f}\right), \\
& \frac{\partial T_{b}}{\partial t}=C_{3}\left(T_{f}-T_{b}\right),
\end{aligned}
$$

Air is adopted as the HTF. All thermo-physical properties of the air are dependent on the temperature $T_{f}$ (see Fig. II). The material chosen for the particles is mostly composed of aluminum oxide, and its thermo-physical properties are also assumed to be dependent on the temperature $\mathrm{T}_{\mathrm{f}}$ (see Fig. II). The average diameter of the packet bed particles is $\mathrm{d}_{\mathrm{S}}=0.008 \mathrm{~m}$, whereas the bed void fraction is $\varepsilon=0.39$.

The temperatures of the hot and cold mass air flow are

$$
\mathrm{T}_{\text {hot }}=237^{\circ} \mathrm{C} \quad \mathrm{T}_{\text {cold }}=38^{\circ} \mathrm{C}
$$

that define the admissible operating range for the temperature profiles in the system, whereas a constant airflow is considered in the loading and unloading phases, namely

$$
\dot{m}_{f}=0.15 \mathrm{~kg} / \mathrm{s}
$$

The coefficients $\mathrm{C}_{1}, \mathrm{C}_{2}, \mathrm{C}_{3}$ depend on the air flow $\dot{m}_{f}$ of the HTF, and furthermore they also vary with the temperature due to the temperature-depedent thermophysical parameter values. The geometrical properties of the tank are:

$$
\begin{array}{cl}
\mathrm{L}=1.8 \mathrm{~m} & \text { Height of the tank } \\
\mathrm{R}=0.292 \mathrm{~m} & \text { Diameter of the tank } \\
\mathrm{A}=\pi \mathrm{R}^{2}=0.26 \mathrm{~m}^{2} & \text { Tank cross section }
\end{array}
$$

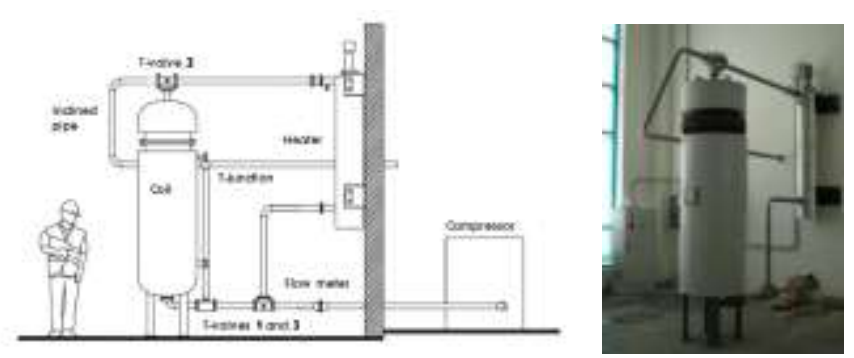

FIGURE I. LABORATORY SETUP SCHEMATICS (LEFT) AND PICTURE (RIGHT)

The nonlinear functions $\mathrm{C}_{1}, \mathrm{C}_{2}, \mathrm{C}_{3}$ are averaged by considering (11) and the admissible temperature range (10), yielding the constant values

- $\mathrm{C} 1=2,3406$ 
Proc. of The Fifth Intl. Conf. On Advances In Computing, Control And Networking - ACCN 2016 Copyright (@ Institute of Research Engineers and Doctors, USA .All rights reserved.

ISBN: 978-1-63248-104-7 doi: 10.15224/ 978-1-63248-104-7-13

- $\quad \mathrm{C} 2=201,1818$

- $\mathrm{C} 3=0,023$

Once the above constant values are replaced into (8)-(9) the original model turns out to be locally linearized and becomes time-invariant. In the next subsection a lumped-parameter finite-dimensional approximation is devised.
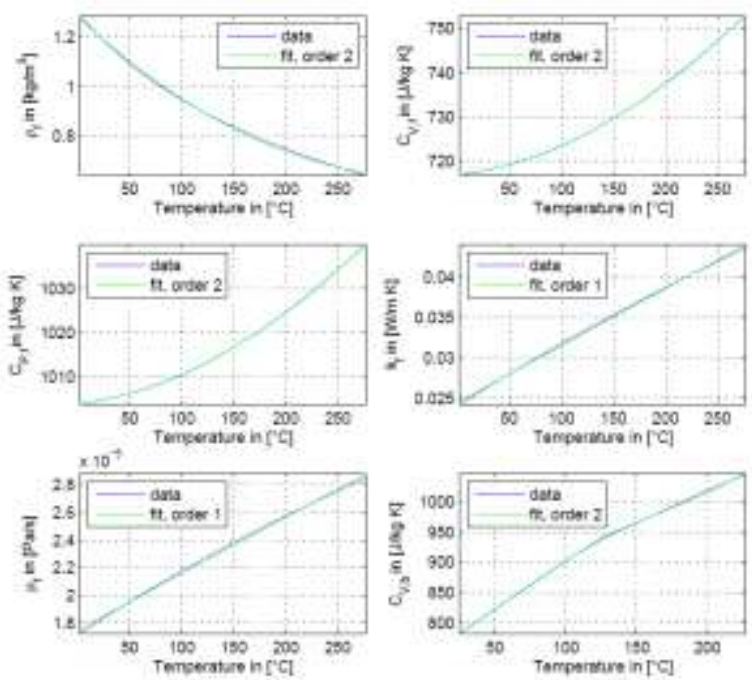

FIGURE II.

THERMOPHYSICAL PROPERTIES OF AIR AND ALUMINA WITH VARYING TEMPERATURE

\section{A. Finite-dimensional LTI model based on finite-difference method}

The spatial domain $[0, \mathrm{~L}]$ is discretized by a uniformly spaced grid $x_{\mathrm{i}}=i d x$, where $\mathrm{i}=0,1, ., \mathrm{M}$ and $d x=\mathrm{L} / \mathrm{M}$. M denotes the number of chosen discretization points.

$\mathrm{T}_{\mathrm{fi}}(\mathrm{t})=\mathrm{T}_{\mathrm{f}}\left(x_{\mathrm{i}}, \mathrm{t}\right)$

$\mathrm{T}_{\mathrm{bi}}(\mathrm{t})=\mathrm{T}_{\mathrm{b}}\left(x_{\mathrm{i}}, \mathrm{t}\right)$,

Approximating the spatial derivative by finite difference method, the following state equation arise:

$\frac{\partial T_{f i}}{\partial t}=-C_{1} \frac{T_{f_{i+1}}-T_{f_{i-1}}}{2 \Delta x}+C_{2}\left(T_{b i}-T_{f i}\right), 1 \leq i \leq M-1$

$\frac{\partial T_{f M}}{\partial t}=-C_{1} \frac{T_{f_{M}}-T_{f_{M-1}}}{\Delta x}+C_{2}\left(T_{b M}-T_{f M}\right)$

$\frac{\partial T_{b i}}{\partial t}=C_{3}\left(T_{f i}-T_{b i}\right) .1 \leq i \leq M$

$\mathrm{T}_{\mathrm{f}}(\mathrm{t})=\left[\mathrm{T}_{\mathrm{f} 1}(\mathrm{t}), \mathrm{T}_{\mathrm{f} 2}(\mathrm{t}), \ldots ., \mathrm{T}_{\mathrm{f}, \mathrm{M}-1}(\mathrm{t}) \mathrm{T}_{\mathrm{f}, \mathrm{M}}(\mathrm{t})\right]$

$T_{b}(t)=\left[T_{b 1}(t), T_{b 2}(t), \ldots . ., T_{b, M-1}(t) T_{b, M}(t)\right]$

The spatial and temporal steps

$$
\Delta x=0.025 \mathrm{~m} \quad \text { Spatial discretization }
$$

\section{$\Delta t=0.0025 \mathrm{~s} \quad$ Temporal discretization}

are chosen in order to satisfy (for each admissible temperature and flow values) the inequality

$$
C F L=\frac{\dot{m}_{f} C_{P, f}}{\rho_{f} \varepsilon C_{V, f} A} \frac{\Delta t}{\Delta x}<1
$$

involving the so-called Courant-Friedrichs-Lewy (CFL) number. The chosen spatial discretization yields $L / \Delta x=72$ spatial "nodes", the value $\mathrm{M}=72$ is thus adopted. The state vector is defined as

$$
T(t)=\left[\begin{array}{llllllll}
T_{f 1} & T_{f 2} & \ldots & T_{f 72} & T_{b 1} & T_{b 2} & \ldots & T_{b 72}
\end{array}\right]^{T}
$$

and the corresponding lumped-parameter model is derived as

$$
\dot{T}(t)=A T(t)+B T_{f, 0}(t)
$$

with the matrices $\mathrm{A}$ and $\mathrm{B}$ as follows

$$
\begin{aligned}
& A=\left[\begin{array}{c|c}
A_{11} & A_{12} \\
\hline A_{21} & A_{22}
\end{array}\right] \\
& A_{11}=\left[\begin{array}{cccccccc}
-C_{2} & -\frac{C_{1}}{2 d x} & 0 & \cdots & \cdots & \cdots & 0 & (24) \\
\frac{C_{1}}{2 d x} & -C_{2} & -\frac{C_{1}}{2 d x} & 0 & \cdots & \cdots & \vdots \\
0 & \ddots & \ddots & \ddots & \ddots & \cdots & \vdots \\
\vdots & \ddots & \ddots & \ddots & \ddots & \ddots & \vdots \\
\vdots & \cdots & \ddots & \ddots & \ddots & \ddots & 0 \\
\vdots & \cdots & \cdots & \ddots & \frac{C_{1}}{2 d x} & -C_{2} & -\frac{C_{1}}{2 d x} \\
0 & \cdots & \cdots & \cdots & 0 & \frac{C_{1}}{d x} & -\frac{C_{1}}{d x}-C_{2}
\end{array}\right] \\
& A_{12}\left.=\left[\begin{array}{cccc}
C_{2} & 0 & \cdots & 0 \\
0 & \ddots & \ddots & \vdots \\
\vdots & \ddots & \ddots & 0 \\
0 & \cdots & 0 & C_{2}
\end{array}\right] \begin{array}{cccc}
A_{21} \\
C_{3} & 0 & \cdots & 0 \\
0 & \ddots & \ddots & \vdots \\
\vdots & \ddots & \ddots & 0 \\
0 & \cdots & 0 & C_{3}
\end{array}\right] \\
&\left.A_{22}=\left[\begin{array}{cccc}
-C_{3} & 0 & \cdots & 0 \\
0 & \ddots & \ddots & \vdots \\
\vdots & \ddots & \ddots & 0 \\
0 & \cdots & 0 & -C_{3}
\end{array}\right] \begin{array}{c}
C_{1} \\
-\frac{C_{1}}{2 d x} \\
0 \\
\vdots \\
0
\end{array}\right]
\end{aligned}
$$

and the temperature profile $T_{f, 0}(t)$ defining the corresponding Dirichlet boundary condition.

\section{OBSERVER DESIGN AND EXPERIMENTAL RESULTS}

In the experimental prototype the fluid temperature $T_{f}$ is measured by temperature sensors embedded into the tank at 19 different vertical locations uniformly spaced along the height 
$\mathrm{L}$ of the tank. The available measurements are a subset of the states of the vector $\mathrm{T}(\mathrm{t})$, defined by an output matrix $\mathrm{C}$. The first and last sensors measure the temperature at the top $(\mathrm{x}=0)$ and bottom $(x=L=1.8 \mathrm{~m})$ side of the tank. Since the height of the tank is $\mathrm{L}=1.8 \mathrm{~m}$, the spacing between the thermocouples is thus $0.1 \mathrm{~m}$.

On the basis of model (23), the Luemberger observer is correspondingly designed as follows

$\hat{\hat{T}}(t)=A \hat{T}(t)+B T_{f, 0}(t)+K_{0}\left(T_{\text {meas }}(t)-\widehat{C T}(t)\right)$

The number $\mathrm{m}$ of measurements passed to the observer is changed from $m=7$ to $m=1$ during several distinct observer design problems under different information availability.

The observer design entails finding an observer gain matrix $\mathrm{K}_{0}$ such that the eigenvalues of the matrix $\mathrm{A}-\mathrm{K}_{0} \mathrm{C}$ lie in the open left plane. The spectrum of eigenvalues of matrix $A$ is entirely contained in the left half plane (see Fig. III) and is composed of two separated branches of "fast" eigenvalues (Fig III-top) and "slow" eigenvalues (Fig. III-bottom)
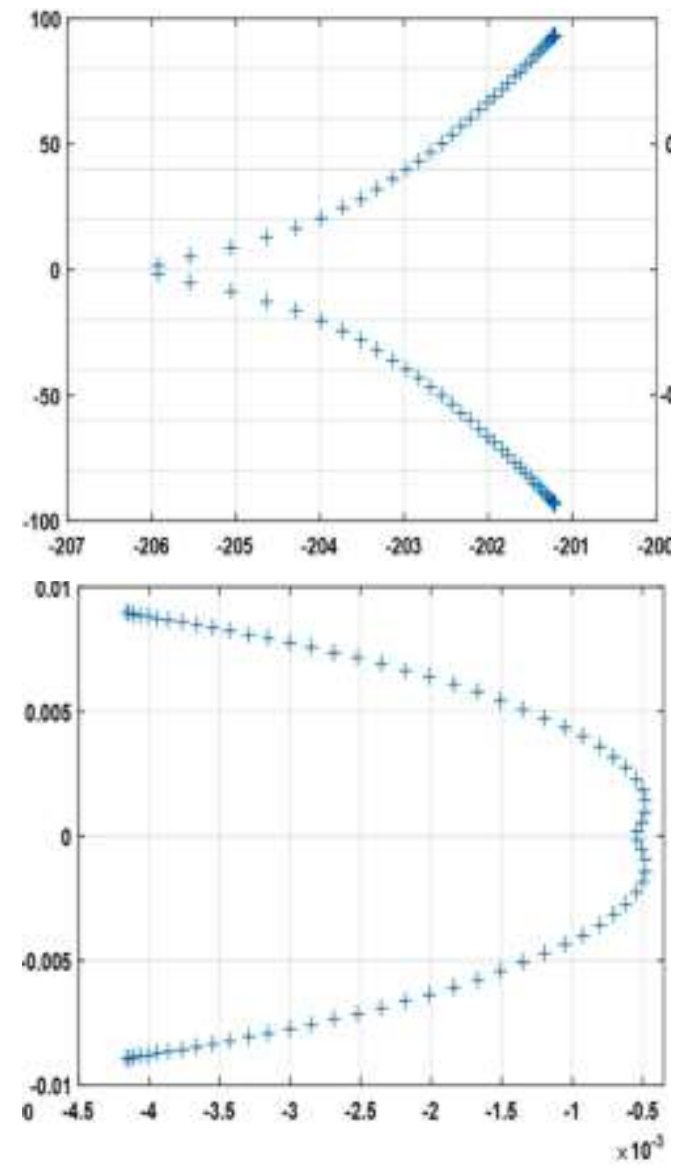

FIGURE III. SPECTRUM OF EIGENVALUES OF MATRIX ATOP: HIGH FREQUENCY EIGENVALUES. DOWN: LOW FREQUENCY EIGENVALUES

Being the system observability matrix ill-conditioned, the location of the eigenvalues of matrix $A-K_{0} C$ cannot be set arbitrarily. The matrix $\mathrm{K}_{0}$ is computed by means of the Matlab place() function to move to the left the low frequency branch of eigenvalues (see the bottom Fig. III) by a fixed amount $p$.

Figure IV shows the results of a first test, where the observer was designed assuming the availability of 7 distinct equispaced measurements. The largest value of $\mathrm{p}$ yielding a stable observer dynamics was found as $\mathrm{p}=\mathrm{p}_{\max }=0.01$, and adopted in the test. Figure IV compares the observed and measured temperature profiles in sensor locations that were not used for designing the observer. The dashed lines denote the observed profiles, whereas the continuous lines denotes the measured ones. The vertical dashed line denotes the end of the charging phase (the system is charged when the temperature of the fluid at the lower end of the cylinder is rising by 7.5 degrees from the initial value.)

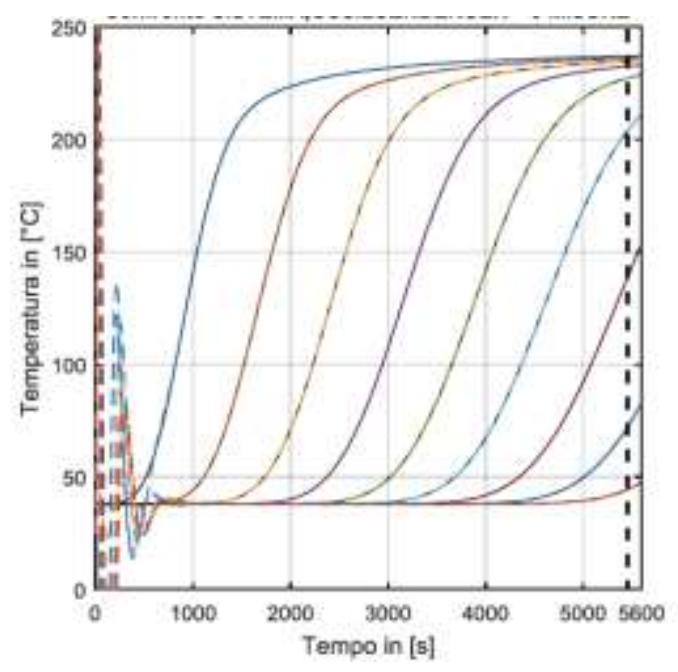

FIGURE IV OBSERVED AND MEASURED TEMPERATURE PROFILES WITH $\mathrm{m}=7$ AND $\mathrm{p}==\mathrm{p}_{\max }=0.01$

Figure V depicts the corresponding actual and observed percentage of charge $\mathrm{PoC}$, computed through the formula

$$
\operatorname{PoC}(t)=\frac{\int_{0}^{L}\left\{T_{b}(x, t)-T_{\text {cold }}\right\}}{L\left(T_{\text {hot }}-T_{\text {cold }}\right)} \times 100
$$

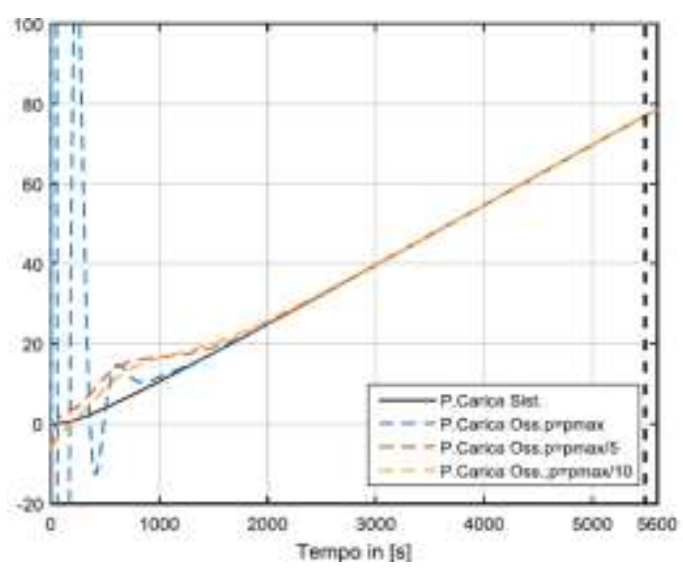

FIGURE V OBSERVED AND ACTUAL PoC WITH m=7 AND DIFFERENT VALUES OF $p$ 
It can be seen from the curves in figure $\mathrm{V}$ that the higher $\mathrm{p}$ is chosen, the faster the convergence of the estimate, but the higher as well the transient oscillations.

In the last test, only a single measurement was passed to the observer. The maximal admissible value for $\mathrm{p}$ in this test was $\mathrm{p}=\mathrm{p}_{\max }=0.0007$. Figure VI compares the performance obtained using different sensor locations (namely, sensor \#2, \#10 and $\# 18$ ). It emerges that using the sensor located in the upper part of the tank (\#2) yields higher transient oscillations of the estimate. Such a transient oscillations is strongly attenuated when the sensors \#10 and \#18 are used. Besides, comparing Figures V and VI it turns out, as expected, that using an higher number $\mathrm{m}$ of measurement sensors in the observer allows a faster reconstruction of the PoC.

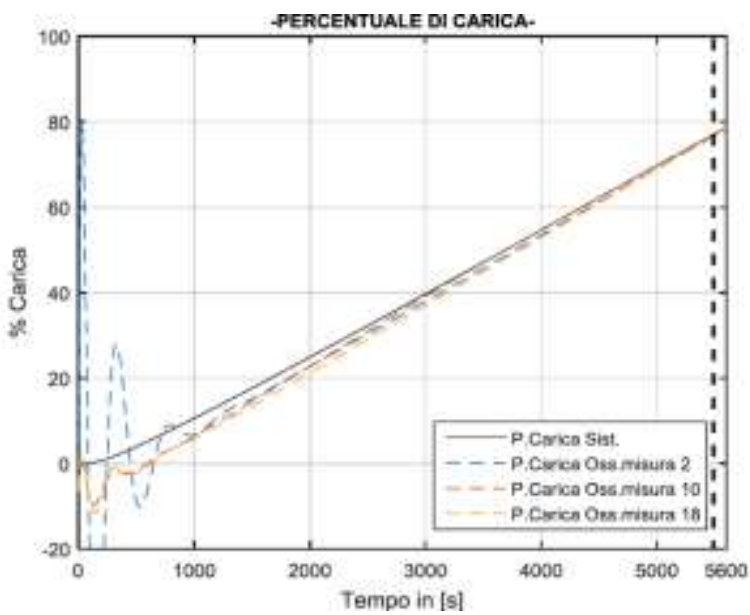

FIGURE VI OBSERVED AND MEASURED PoC WITH $\mathrm{m}=1$ AND DIFFERENT SELECTION OF THE MEASUREMENT POINT

\section{CONCLUSIONS}

With reference to the packed-bed heat storage apparatus, a Luenberger state observer has been designed, and experimentally verified, in order to reconstruct the internal fluid and packed-bed temperature profiles and the percentage of charge of the tank. Further activities will investigate different observer designs such as Extended Luenberger observer or Kalman filters. Besides, the design of an infinite dimensional observer, not relying on any prior discretization of the mathematical model, is under investigation.

\section{ACKNOWLEDGMENTS}

The research leading to these results has received funding from the research project "Modeling, control and experimentation of innovative thermal storage systems", funded by Sardinia regional government under grant agreement n. CRP-60193

\section{REFERENCES}

[1] P. Li Energy storage is the core of renewable energy technologies. IEEE Nanotechnol Mag 2008;4:3-18.
[2] G.J. Kolb Economic evaluation of solar-only and hybrid power towers using molten-salt technology. Sol Energy vol. 62, pp. 51-61, 1998.

[3] US Department of Energy, SunShot vision study, February 2012. p. 115 [chapter 5].

[4] Schmidt FW, Willmott AJ. Thermal energy storage and regeneration. Washington, DC: Hemisphere Pub. Corp; 1981.

[5] S.M. Hasnain "Review on sustainable thermal energy storage technologies, Part I: heat storage materials and techniques". Energy Convers Manag; vol. 39, :pp. 1127-1138, 1998

[6] U. Herrmann, DW Kearney Survey of thermal energy storage for parabolic trough power plants. ASME Trans J Sol Energy Eng, vol. 124, pp. 145-52, 2002.

[7] Zalba B, Marin JM, Cabeza LF, Mehling H. Review on thermal energy storage with phase change: materials, heat transfer analysis and applications. Appl Therm Eng 2003;23:251-83

[8] A. Gil et al., State of the art on high temperature thermal energy storage for power generation. Part 1 - Concepts, materials and modellization, Renewable and Sustainable Energy Reviews 14 (2010) $31-55$.

[9] Brosseau D, Kelton JW, Ray D, Edgar M, Chisman K, Emms B. Testing of thermocline filler materials and molten-salt heat transfer fluids for thermal energy storage systems in parabolic trough power plants. J Solar Energy Eng-Trans ASME 2005;127:109-16.

[10] J. Coutier, E. Farber, Two applications of a numerical approach of heattransfer process within rock beds, Sol. Energy 29 (6) pp. 451-462, 1982.

[11] G. Adebiyi, E. Nsofor, W. Steele, A. Jalalzadeh-Azar, Parametric study on the operating efficiencies of a packed bed for high-temperature sensible heat storage, ASME J. Sol. Energ. Eng. 120 (1) (1998) 2-13.

[12] T. Schumann, Heat transfer: a liquid flowing through a porous prism, J. Franklin Inst. 208 (1929) 405-416.

[13] K. Ismail, R. Stuginsky, A parametric study on possible fixed bed models for pcm and sensible heat storage, Appl. Therm. Eng. 19 (7) (1999) 757 788.

[14] Harmeet Singh, R.P. Saini, J.S. Saini, A review on packed bed solar energy storage systems, Renewable and Sustainable Energy Reviews, vol. 14, n. 3, pp. 1059-1069, 2010

[15] K. Ismail, R. Stuginsky, A parametric study on possible fixed bed models for pcm and sensible heat storage, Appl. Therm. Eng., vol. 19, n. 7, pp. 757-788, 1999.

[16] M. Cascetta, G. Cau, P. Puddu, F. Serra, Numerical investigation of a packed bed thermal energy storage system with different heat transfer fluids, Energy Procedia, vol. 45, pp. 598 - 607, 2014

[17] A. Vande Wouwer, and M. Zeitz. IState estimation in distributed parameter systems". In H. Unbehauen (Ed.), Encyclopedia of life support systems (EOLSS). Oxford, UK: EOLSS Publishers, (Chapter) Control systems, robotics and automation, Article No. 6.43.19.3, 2001.

[18] Z. Hidayat, R. Babuska, B. De Schutter, and A. Nunnez, "Observers for linear distributed-parameter systems: A survey" Proc. 2011 IEEE International Symposium on Robotic and Sensors Environments (ROSE 2011), Montreal, Canada, pp. 166.171, 2011.

[19] R. Vazquez, and M. Krstic, Boundary Observer for Output-Feedback Stabilization of Thermal-Fluid Convection Loop IEEE Trans. Contr. Syst. Tech., 18(4), 789-797, 2010.

[20] D. Tsubakino, and S. Hara \Backstepping observer design for parabolic PDEs with measurement of weighted spatial averages, Automatica, Volume 53, March 2015, Pages 179187

[21] D. Dejaco, et al. Numerical Investigation of Packed-Bed Thermal Energy Storage Systems with Prediction-based Adjustment of the Heat Transfer Fluid Flow. International Journal of Advances in Electronics Engineering-IJAEE, vol. 6, n. 1, 2016.

[22] D. G. Luenberger, An introduction to observers," IEEE T. Automat. Contr., vol. 16, no. 6, pp. 596-602, Dec. 1971.

[23] J. H. Lilly, "Finite-dimensional adaptive observers applied to distributed parameter systems," IEEE T. Automat. Contr., vol. 38, no. 3, pp. 469474, Mar. 1993. 